\title{
Effect of PCI on QTC Dispersion in Patients with Angina
}

\section{SHAFIQUL ISLAM, SHEKHAR KUMAR MONDAL , JAFRIN JAHAN, MINHAJ AREFIN, NISHAT AHMED,} PINAKI RANJAN DAS, M.G.AZAM

\author{
Department of Cardiology, National Institute of Cardiovascular Diseases( NICVD), Dhaka, Bangladesh \\ Address of Correspondence: Prof. M. G . Azam, Department of Cardiology, National Institute of Cardiovascular Diseases( \\ NICVD), Dhaka, Bangladesh. E-mail:mgazam71@yahoo.com
}

\begin{abstract}
:
Background: 'Coronary heart disease (CHD) is now the leading cause of death worldwide; it is on the rise and has become a true pandemic that respects no borders. For the diagnosis of coronary artery disease, the 12 leads electrocardiogram (ECG) is the most readily available non invasive test by which, in addition of diagnosis, localizing and estimating the size of myocardial ischemia can be determined. Abnormally high QT dispersion has been correlated with risk of arrhythmic death in various cardiac diseases including CAD. An increase in QTd is reported to predict the occurrence of life-threatening ventricular tachyarrhythmias and sudden cardiac death in patients with ischemic heart disease. Materials and Methods: This Cross sectional analytical study was conducted in Department of Cardiology, National Institute of Cardiovascular Diseases, Dhaka from January 2013 to December 2013. A total of 100 consecutive patients with angina based on predefined enrollment criteria were included in the study. . All patients were evaluated by history, clinical examination, biochemical analysis, and coronary angiogram (CAG) which was performed during index hospital admission. PCI was done only if the vessel was significantly stenosed.i,e. for LMCA - e "50\%, for LAD, LCX and RCA it was e"70\% as significant stenosis. Severity of stenosis of the involved vessels were categorized as severe( $e^{\text {"90\%) and }}$ moderate $(<90 \%)$. Results: Among the study population 76 (76\%) patients were male and 24 (24\%) patients were female. The left anterior descending artery (LAD) group comprised 37 patients and there were significant differences between before and after PCI QTc dispersion (90.5 \pm 38.9 vs $70.4 \pm 39.6 \mathrm{~ms}, \mathrm{p}=0.001$ ). The left circumflex artery (LCX) group was comprised of 6 patients and there were significant differences between before and after PCI QTc dispersion (62.2 \pm 41.9 vs $50.2 \pm 37.2 \mathrm{~ms}, p=0.001)$. The right coronary artery (RCA) group consisted of 18 patients, there being significant differences between before and after PCI QTc dispersion (84.9 \pm 40.7 vs 69.1 $\pm 41.5 \mathrm{~ms}, \mathrm{p}=0.001)$ Conclusion: PCI reduces QTc dispersion significantly among patients with angina. This QTc dispersion change is not influenced by sex, smoking, beta-blockers, hypertension, diabetes, renal impairment, stable or unstable angina but it depends upon the severity of coronary artery stenosis, involvement of coronary vessel and number of vessels. Reduction of QTc dispersion is a good sign of successful PCI that indicates successful reperfusion which carries an excellent prognostic value of revascularization. Further long term follow up will establish it.
\end{abstract}

Key words: Percutaneous Coronary Intervension (PCI), QT corrected dispersion (QTc dispersion) Left Anterior descending Artery (LAD), Left Circumflex artery (LCX), Right Coronary Artery ( RCA)

University Heart Journal 2020; 16(1): 33-39

Introduction:

'Coronary heart disease (CHD) is now the leading cause of death worldwide; it is on the rise and has become a true pandemic that respects no borders'. ${ }^{1}$ This statement from 2009 on the website of the WHO does not differ much from the warning issued in 1969 by its Executive Board: 'Mankind's greatest epidemic: CHD has reached enormous proportions striking more and more at younger subjects. It will result in coming years in the greatest epidemic mankind has faced unless we are able to reverse the trend by concentrated research into its cause and prevention. $^{2}$
Cardiovascular disease is the leading cause of death worldwide, affecting not only high-income but also lowand middle-income countries. Nearly 80 percent of all estimated cardiovascular disease related deaths worldwide now occur in low- and middle-income countries, where nearly 30 percent of all deaths are attributable to cardiovascular disease. ${ }^{3}$

The South Asian countries of India, Pakistan, Bangladesh, Srilanka and Nepal contribute the highest proportion of the burden of Cardiovascular Diseases (CVDs) compared to any other region globally. ${ }^{4}$ 
According to one survey, prevalence rate of ischaemic heart disease in Bangladesh was 3.4\% in 2001. 5

For the diagnosis of coronary artery disease, the 12 leads electrocardiogram (ECG) is the most readily available non invasive test by which, in addition of diagnosis, localizing and estimating the size of myocardial ischemia can be determined. Prior to the technologic revolution in noninvasive cardiac imaging of the 1970S and 1980s, the ECG and chest X-ray were the most commonly performed tests to cardiac diagnosis.

QT interval on the surface electrocardiogram (ECG) is a measure of total time of ventricular depolarization and repolarization(Fig-1). Regional differences in ventricular repolarization are reflected as differences in QT intervals in leads corresponding to different part of the myocardium. This heterogeneity is called QT interval dispersion. ${ }^{6}$ Abnormally high QT dispersion has been correlated with risk of arrhythmic death in various cardiac diseases including CAD. ${ }^{7}$

An increase in QTd is reported to predict the occurrence of life-threatening ventricular tachyarrhythmias and sudden cardiac death in patients with ischemic heart disease. $^{8}$

QT dispersion significantly increased during spontaneous angina in patients with documented CAD and were found to be significantly higher during the anginal episode compared to the painless conditions. ${ }^{9}$ Prolonged QTc dispersion correlates with coronary artery disease severity in acute ST elevation myocardial infarction. ${ }^{10}$

It is well established that ischemia can increase QT dispersion. Percutaneous coronary intervention is widely performed to manage ischemia in patients with coronary artery disease. So it is speculated that PCI can also reduce QT dispersion.

QT interval dispersion decreases after successful coronary artery revascularization and increases with restenosis.$^{11}$ Therefore, QT interval dispersion may be a marker of prognosis after PCI.

\section{QTe dispersion in normal subjects}

Literature reviews found that QT dispersion to vary mostly between 30 and $60 \mathrm{~ms}$ in normal subjects, ${ }^{13}$ although average values around $70 \mathrm{~ms}$ were also reported.

Different studies show no statistically significant difference in QT dispersion between the genders or marginally greater values in men. ${ }^{14,15}$

\section{Prognostic value of QTe dispersion}

Prolonged QT dispersion as a poor prognostic factor for CAD. They found prolonged QT dispersion is associated with higher level of Troponin $\mathrm{T}$ which is a recognized factor of poor prognosis of CAD. ${ }^{16}$

QTd and QTcd were decreased significantly after PTCA+ Stent because of the improvement of myocardial ischemia and heterogeneous repolarization in patients with coronary heart disease. ${ }^{17}$ The degree in decreasing QTd and QTcd was associated with compensatory circulation in coronary artery.

\section{Materials and Methods:}

In this Cross sectional analytical study was carried out in the department of cardiology at NICVD, Dhaka over a period of 1 year from January 2013 to December 2013. during the period a total 100 patients was taken as study population and inclusion criteria was Patients with chronic stable angina and unstable angina undergoing PCI with Angiographic evidence of significant stenosis, e" $50 \%$ for left main and $\geq 70 \%$ for any other major coronary vessel . At least one major vessel should have a significant stenosis. Exclusion criteria was Acute myocardial infarction, Ventricular pacing, Patients not in sinus rhythm, Sustained monomorphic ventricular tachycardia . Congenital long QT syndrome, Chronic total occlusion ,Electrolyte imbalance was excluded in this study. The study protocol approved by the institutional review board. Informed consent was taken from each patient or near relatives. Meticulous history were taken and detailed clinical examination were performed and recorded in predesigned structured sheet. Demographic data such as age, sex, height, weight, occupation etc. were recorded. Risk factors profile included tobacco consumption, hypertension, diabetes, dislipidaemia, family history of CAD were noted. Laoratory investigations were done Cardiac Troponin-I, S. Creatinine, Blood Sugar, Lipid profile, screening blood tests for PCI were done

ECG: Two 12 lead resting ECG were recorded, one on the morning of PCI day and another one 24 hours after PCI, at a paper speed of $25 \mathrm{~mm} / \mathrm{s}$ and $10 \mathrm{~mm} / \mathrm{mV}$ standardization.

\section{Measurement of QTc dispersion:}

QT dispersion was calculated on standard resting 12 lead ECGs obtained at the time of admission at a paper speed of $25 \mathrm{~mm} / \mathrm{sec}$ and with a calibration of $1 \mathrm{mv}$. Where at least 9 leads show measurable QT interval. ECG is manually measured with hand help calipers.QT interval was measured from the beginning of the inscription of the QRS complex to the point at which the $\mathrm{T}$ wave returned to the isoelectric line (Return to the TP base line). ${ }^{15}$ For calculation of QT dispersion, 3 consecutive cycles were 
measured in each lead and the mean of these 3 cycles was taken as mean QT interval of that lead. In case of U wave, termination of the $\mathrm{T}$ wave was defined as the nadir of the curve between the $\mathrm{T}$ and $\mathrm{U}$ waves. Leads where the $\mathrm{T}$ wave ends or $\mathrm{T}$ wave morphology could not be clearly observed was excluded from analysis. ${ }^{16}$ The QT interval was corrected by using Bazett's formula $(\mathrm{QTc}=\mathrm{QT} / \mathrm{square}$ root of R-R interval in seconds).Corrected QT dispersion (QTcd) was defined as the difference between the maximum and minimum QTc for a given heart rate.

So QTcd=QTc maximum- QTc minimum . The normal mean QTcd is $45+--\_15 \mathrm{~ms} .{ }^{17}$

\section{Observation and Results:}

A total of 100 patients with chronic stable angina and unstable angina undergoing successful PCI were included in the study. $76(76 \%)$ patients were male and $24(24 \%)$ patients were female. Male female ratio was 3.2:1. Majority of the study patients belonged to 51-60 years age $42 \%$ followed by $32 \%, 15 \%$ and $11 \%$ in $41-50,>60$ and $\mathrm{d}$ " 40 years respectively. The mean age was found $52.6 \pm 9.1$ years in male and 55.4 \pm 9.9 years in female patients (table-1). Among the study patients, smoking was found $73 \%$ followed by hypertension $50 \%$, diabetes mellitus $49 \%$, family history of CAD and OMI $23 \%$ and dyslipidemia $13 \%$ (fig-2). The mean systolic blood pressure was $129.7 \pm 15.7 \mathrm{mmHg}$ and mean diastolic blood pressure was $82.0 \pm 8.7 \mathrm{mmHg}$ (Table-2). Among the study population $64 \%$ patients diagnosed as chronic stable angina and $36 \%$ patients diagnosed as unstable angina. QTc dispersion before PCI and after PCI were observed $85.2 \pm 41.4 \mathrm{~ms}$ and $68.8 \pm 40.8 \mathrm{~ms}$ respectively (table-3). The difference was statistically significant $(\mathrm{p}=0.001)$. That is, QTc dispersion reduced significantly after PCI. Before PCI, the mean QTc dispersion was observed $90.8 \pm 41.0 \mathrm{~ms}$ and $74.2 \pm 40.8 \mathrm{~ms}$ after PCI in male patients with significant difference $(p=0.001)$. It was also observed that in female, before PCI mean QTc dispersion was 67.4 $\pm 37.9 \mathrm{~ms}$ and after PCI it was52.0 $\pm 37.0 \mathrm{~ms}$. with significant difference $(\mathrm{p}=0.001)$ (Table-IV).. The patients were also analyzed according to their involved arteries (Table-V). QTc dispersion according to risk factors like as smoking, hypertension, diabetes mellitus and kidney dysfunction. No significant difference was observed in differences of QT dispersion among the patients according to risk factors ( $p>0.05$ ) (Table-VI). Change of QTc dispersion according to gender (16.8 \pm 7.8 vs $15.4 \pm 6.6, p=0.44)$ of male and female patients respectively (Table-VII). No significant difference in QT dispersion was observed between male and female patients. There was significant association between change of QTc dispersion and vessel involvement of the study patients (Table-VIII). There was no significant association between change of QTc dispersion and severity of stenosis of the study patients (table-IX). Change of QTc dispersion according to ischemic heart disease (14.6 \pm 8.1 vs $17.5 \pm 6.9, \mathrm{p}=0.06)$ of CSA and UA patients respectively (Table-X). There was no significant difference in baselione QT dispersion among the patients with CSA and UA, though the change of reduction was more in UA than CSA.

Table-I

Age and sex distribution of the study patients

\begin{tabular}{|c|c|c|c|c|c|c|c|}
\hline \multirow[t]{2}{*}{ Age in years } & \multicolumn{2}{|c|}{ Male $(n=76)$} & \multicolumn{2}{|c|}{ Female $(n=24)$} & \multicolumn{2}{|c|}{$\operatorname{Total}(n=100)$} & \multirow[t]{2}{*}{$p$ value } \\
\hline & Number & $\overline{\%}$ & Number & $\overline{\%}$ & Number & $\%$ & \\
\hline d" 40 & 9 & 11.2 & 2 & 8.3 & 11 & 11.0 & \\
\hline $41-50$ & 24 & 31.3 & 8 & 33.3 & 32 & 32.0 & \\
\hline $51-60$ & 35 & 46.1 & 7 & 29.2 & 42 & 42.0 & \\
\hline$>60$ & 8 & 10.5 & 7 & 29.2 & 15 & 15.0 & \\
\hline $\begin{array}{l}\text { Mean } \pm \text { SD } \\
\text { (Range) }\end{array}$ & \multicolumn{2}{|c|}{$52.6 \pm 9.1(30-71)$} & \multicolumn{2}{|c|}{$55.4 \pm 12.1(32-75)$} & \multicolumn{2}{|c|}{$53.3 \pm 9.9(30-75)$} & $0.23^{\mathrm{ns}}$ \\
\hline
\end{tabular}

$\mathrm{ns}=$ Not significant $(\mathrm{p}>0.05) \quad \mathrm{P}$ value reached from unpaired $\mathrm{t}$-test

Table II

Distribution of the study patients according to clinical examinations

\begin{tabular}{lc}
\hline Clinical examination & Mean \pm SD \\
\hline Pulse/min & $82.7 \pm 8.2$ \\
Systolic Blood pressure $(\mathrm{mmHg})$ & $129.7 \pm 15.7$ \\
Diastolic Blood pressure $(\mathrm{mmHg})$ & $82.0 \pm 8.7$ \\
\hline
\end{tabular}


Table-III

QTc dispersion status of the study patients

\begin{tabular}{lccc}
\hline Variable & Before PCI & After PCI & p value \\
\hline & Mean \pm SD & Mean \pm SD & \\
QTc dispersion & $85.2 \pm 41.4 \mathrm{~ms}$ & $68.8 \pm 40.8 \mathrm{~ms}$ & $0.001^{\mathrm{s}}$ \\
\hline
\end{tabular}

Table IV

Sex wise QTc dispersion status of the study patients

\begin{tabular}{lccc}
\hline Sex & Before PCI & After PCI & P value \\
\hline & Mean \pm SD & Mean \pm SD & \\
Male $(\mathrm{n}=76)$ & $90.8 \pm 41.0 \mathrm{~ms}$ & $74.1 \pm 40.8 \mathrm{~ms}$ & $0.001^{\mathrm{s}}$ \\
Female $(\mathrm{n}=24)$ & $67.4 \pm 37.9 \mathrm{~ms}$ & $52.0 \pm 37.0 \mathrm{~ms}$ & $0.001^{\mathrm{s}}$ \\
\hline
\end{tabular}

Table-V

QTc dispersion changes status according to the involvement of coronary arteries

\begin{tabular}{lccc}
\hline Involved arteries & Before PCI & After PCI & P value \\
\hline & Mean \pm SD & Mean \pm SD & \\
$\operatorname{LAD}(\mathrm{n}=37)$ & $90.5 \pm 38.9 \mathrm{~ms}$ & $70.4 \pm 39.6 \mathrm{~ms}$ & $0.001^{\mathrm{s}}$ \\
$\operatorname{LCX}(\mathrm{n}=6)$ & $62.2 \pm 41.9 \mathrm{~ms}$ & $50.2 \pm 37.2 \mathrm{~ms}$ & $0.001^{\mathrm{s}}$ \\
$\mathrm{RCA}(\mathrm{n}=18)$ & $84.9 \pm 40.7 \mathrm{~ms}$ & $69.1 \pm 41.5 \mathrm{~ms}$ & $0.001^{\mathrm{s}}$ \\
\hline
\end{tabular}

Table-VI

Comparison between change of QTc dispersion and risk factors

\begin{tabular}{|c|c|c|c|c|}
\hline \multicolumn{2}{|c|}{ Variables } & \multicolumn{2}{|c|}{ Differences of QTc dispersion in $\mathrm{ms}$} & \multirow[t]{2}{*}{$\mathrm{P}$ value } \\
\hline & & Mean & $\mathrm{SD}$ & \\
\hline \multirow[t]{2}{*}{ Smoking } & Smoker $(n=73)$ & 16.4 & 6.5 & $0.58^{\mathrm{ns}}$ \\
\hline & Non-smoker $(\mathrm{n}=27)$ & 17.6 & 7.8 & \\
\hline \multirow[t]{2}{*}{ Hypertension } & Hypertensive $(\mathrm{n}=50)$ & 16.3 & 7.4 & $0.84^{\mathrm{ns}}$ \\
\hline & Normotensive $(\mathrm{n}=50)$ & 16.6 & 7.6 & \\
\hline \multirow[t]{2}{*}{ Diabetes } & Diabetic $(n=49)$ & 15.7 & 6.7 & $0.36^{\mathrm{ns}}$ \\
\hline & Non-diabetic $(\mathrm{n}=51)$ & 17.1 & 8.1 & \\
\hline \multirow[t]{2}{*}{ Serum creatinine } & Abnormal (> $1.2 \mathrm{mg} / \mathrm{dl})(\mathrm{n}=15)$ & 16.2 & 4.8 & $0.49^{\text {ns }}$ \\
\hline & $\operatorname{Normal}(\leq 1.2 \mathrm{mg} / \mathrm{dl})(\mathrm{n}=85)$ & 16.6 & 5.6 & \\
\hline
\end{tabular}

Table-VII

Comparison of change of QTC dispersion after PCI according to gender status

\begin{tabular}{lccc}
\hline Gender & \multicolumn{2}{c}{ Differences of QTc dispersion in $\mathrm{ms}$} & P value \\
\cline { 2 - 3 } & Mean & SD & \\
\hline Male $(\mathrm{n}=76)$ & 16.8 & 7.8 & $0.44^{\text {ns }}$ \\
Female $(\mathrm{n}=24)$ & 15.4 & 6.6 & \\
\hline
\end{tabular}




\section{Table-VIII}

Association between change of QTc dispersion and number of vessels involved

\begin{tabular}{|c|c|c|c|}
\hline \multirow[t]{2}{*}{ No. of vessel involved } & \multicolumn{2}{|c|}{$\begin{array}{l}\text { Differences of QTc dispersion in ms } \\
\text { (QTc dispersion reduced) }\end{array}$} & \multirow[t]{2}{*}{$\mathrm{P}$ value } \\
\hline & Mean & SD & \\
\hline Single $(\mathrm{n}=61)$ & 14.9 & 7.9 & $0.007^{\mathrm{s}}$ \\
\hline Double $(\mathrm{n}=37)$ & 18.9 & 6.0 & \\
\hline
\end{tabular}

Table-IX

Comparison of change of QTC dispersion and severity of stenosis

\begin{tabular}{lccc}
\hline Stenosis in \% & \multicolumn{2}{c}{ Differences of QTc dispersion in $\mathrm{ms}$} & p value \\
\cline { 2 - 3 } & Mean & SD & \\
\hline Severe (e" $90 \%) \mathrm{n}=69$ & 17.3 & 7.5 & $0.09^{\text {ns }}$ \\
Moderate $(<90 \%) \mathrm{n}=31$ & 14.6 & 7.2 & \\
\hline
\end{tabular}

Table-X

Comparison between change of QTC dispersion after PCI and type of IHD

\begin{tabular}{lccc}
\hline Diagnosis & \multicolumn{2}{c}{ Differences of QTc dispersion in ms } & P value \\
\cline { 2 - 3 } & Mean & SD & \\
\hline CSA $(\mathrm{n}=64)$ & 14.6 & 8.1 & $0.06^{\text {ns }}$ \\
$\mathrm{UA}(\mathrm{n}=36)$ & 17.5 & 6.9 & \\
\hline
\end{tabular}
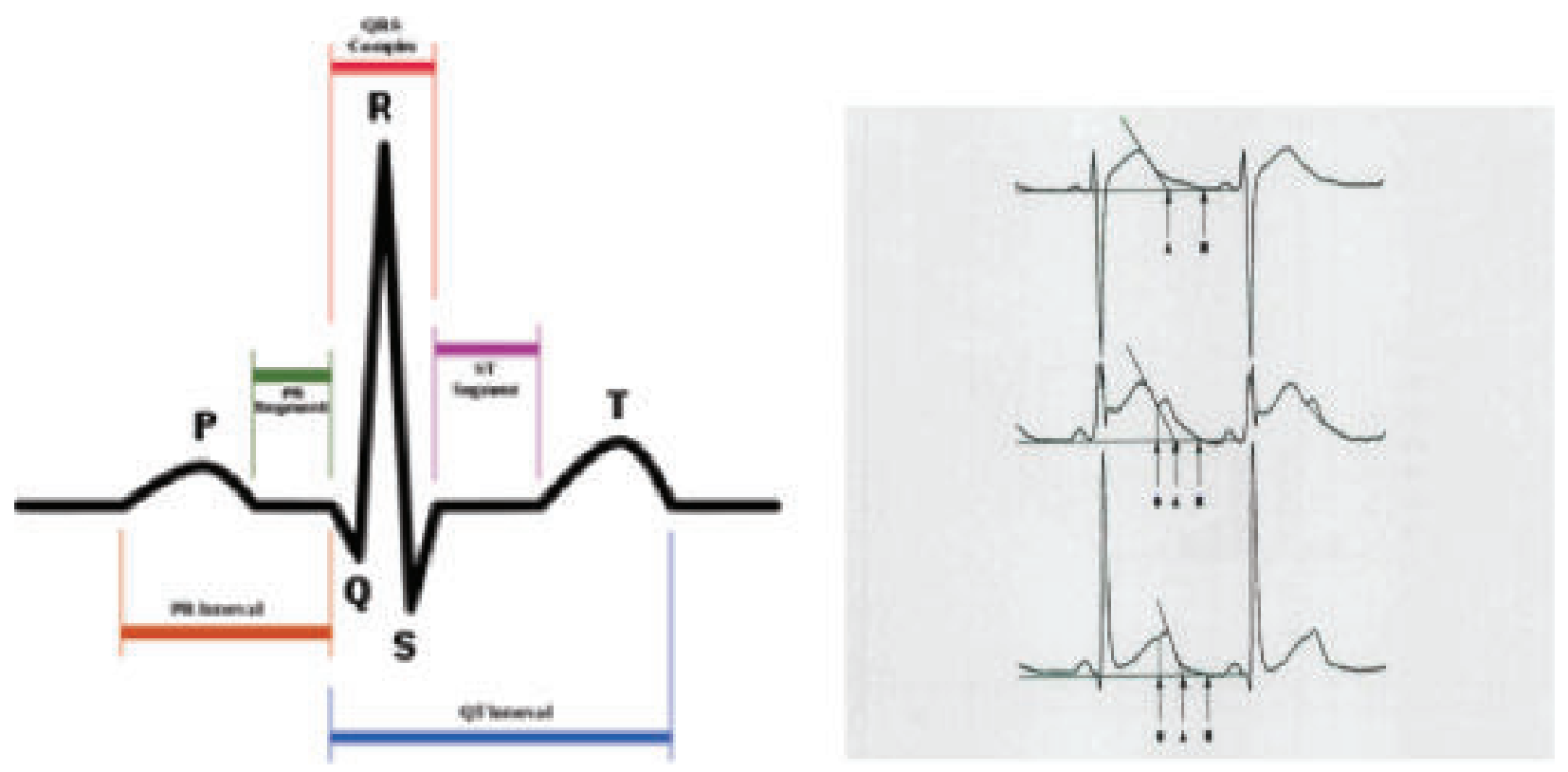

Fig.-1: Measurement of QT interval (Bruyne, et al, 1999) 


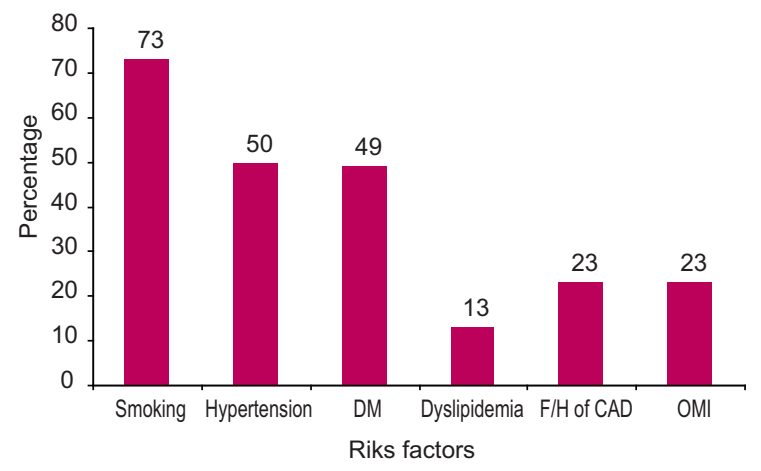

Fig.-2: Distribution of study patients according to risk factors $(n=100)$

\section{Discussion:}

In our study. we found the mean age of the patients was $53.3 \pm 9.9$ years. Maximum frequency was found in the age group of 41-60 years.Almost similar mean age was observed by Yilmaz,et al. ${ }^{18}$, Tikiz,et al. ${ }^{19}$, which are comparable with the current study.In this study it was observed that among 100 patients $76(76 \%)$ patients were male and $24(24 \%)$ patients were female which was almost similar $72 / 28$ as observed by observed by Zhang Y et al. ${ }^{15}$

The common risk factors for coronary artery disease in the present study were smoking $(73 \%)$, the highest one followed by hypertension( $50 \%$ ), diabetes mellitus (49\%), family history of $\mathrm{CAD}(23 \%)$, and dislipidemia(13\%). Almost similar distribution of risk factors were observed by Sharafat et al. ${ }^{10}$ and Uddin et al ${ }^{20}$ found smoking as the highest prevalent risk factor. This finding of the risk factors was similar regarding smoking habit \& dyslipidemia with the study conducted by Tikiz et al. ${ }^{15}$

\section{Change of QTc dispersion after PCI}

In our study, we found that QTc dispersion of the study population, before $\mathrm{PCI}$ was $82.4 \pm 21.4 \mathrm{~ms}$ and after PCI was $64.6 \pm 21.7 \mathrm{~ms}$ which was statistically $\operatorname{significant}(\mathrm{p}=0.001)$ and the reduction of QTc dispersion was about $18 \mathrm{~ms}$ which was almost similarly observed by Alasti et al. ${ }^{23}$ In their study, QTc dispersion before PCI was $80 \pm 40 \mathrm{~ms}$ and after PCI it was $60 \pm 40 \mathrm{~ms}$.

Reduction of QTc dispersion after PCI was also observed by Choi K-J et al. ${ }^{21} 16 \pm 4.3 \mathrm{~ms}$, Kelly RF et al. ${ }^{3} 80 \pm 12 \mathrm{ms,}$, TAKASE B et al. $.^{22} 26 \pm 16 \mathrm{~ms}$, Zhang Y et al. ${ }^{15}$ etc.

This reduction of QTc dispersion indicates successful revascularization after PCI and improvement of ischemia burden due to reperfusion.

We found in our study that among 100 patients, 61(61\%) patients had single vessel disease, 37(37\%) patients had double vessels disease and $2(2 \%)$ patients had triple vessels disease. It was observed that prolonged QT duration was associated with the increasing number of affected vessels.

Accordingly, change of QTc dispersion was found for SVD-14.9 \pm 7.9 , for DVD-18.9 \pm 6.0 and for TVD- it was $19.3 \pm 5.6 \mathrm{~ms}$ ( $\mathrm{p}$ value $=0.01$ ). Here we see that increasing the number of involved vessel, there is increased reduction in QTc dispersion after PCI.

We analyzed the change of QTc dispersion before and after PCI according to the severity of stenosis i,e. e" $90 \%$ vs $<90 \%$. It was found that reduction of QTc dispersion was more $(17.3 \pm 7.5 \mathrm{~ms})$ in case of severe stenosis than moderate stenosis $(14.6 \pm 7.2 \mathrm{~ms})$ but it was not statistically significant. Similar observation was seen in the study by Choi K-J et al. ${ }^{21}$

In this study we observed the change of QTc dispersion among the patients according to involvement of different coronary artery and found that in case of LAD; $16 \pm 40.3 \mathrm{~ms}$, in case of RCA; $17.3 \pm 41.7 \mathrm{~ms}$, and in case of LCX $13.54 \pm 42.4 \mathrm{~ms}$. Here we see the reduction of QTc dispersion was highest for LAD followed by RCA and LCX. But this difference was not also statistically significant. Similar observation was found in the study by Choi et al. ${ }^{21}$

In our study we found an association between QTc dispersion change and number of vessel involvement. Patients those had single vessel involvement had mean QTc dispersion change $14.9 \pm 7.9 \mathrm{~ms}$, patients those had double vessel disease mean QTc dispersion change was $18.9 \pm 6.0 \mathrm{~ms}$ and patients those with triple vessel involvement had mean QTc dispersion change was $19.3 \pm 5.6 \mathrm{~ms}$. There is a strong positive correlation with the QTc dispersion change and increasing number of vessel involvement and was observed significant by Spearman's correlation test $(\mathrm{p}=0.01)$.

The most important finding of this study is that prolonged QTc dispersion is shortened by successful percutaneous coronary intervention (PCI). Thus help us as an important index for successful reperfusion and plays an important role in the prognosis of post PCI patients.

\section{Conclusion:}

PCI reduces QTc dispersion significantly among patients with angina. This QTc dispersion change is not influenced by sex, smoking, beta-blockers, hypertension, diabetes, renal impairment, stable or unstable angina but it depends upon the severity of coronary artery stenosis, involvement of coronary vessel and number of vessels. 
Reduction of QTc dispersion is a good sign of successful PCI that indicates successful reperfusion which carries a excellent prognostic value of revascularization. Further long term follow up will establish it.

\section{References:}

1. American College of Cardiology Foundation,. ACCF/ AHA/ ACP/ AATS/ PCNA/ SCAI/ STS Guideline for the Diagnosis and Management of Patients with Stable Ischemic Heart Disease, journal of the American College of Cardiology, 2012;60(24):44-164.

2. World Health Organization Regional Office for Europe. The Prevention and Control of Major Cardiovascular Diseases: Report of a Conference. Report No. Euro 1973, 8214

3. . Kelly RF, Parillo JE, Hollenberg SM. Effect of coronary angioplasty on QT dispersion. Am Heart J. 1997;134:399405 .

4. Yusuf S, Reddy S, Ounpuu S, Anand S. Global burden of cardiovascular diseases: part I: general considerations, the epidemiologic transition, risk factors, and impact of urbanization. Circulation. 2001;27;104(22):2746-53.

5. Zaman MM, Ahmed J, Chowdhury SR,Numan SM, Parvin K, Islam MS. Prevalence of ischemic heart disease in a rural population of Bangladesh. Indian Heart J. 2007;59(3):23941.

6. Döven, D., Özdol,C., Sayin, T. and Dervis, O. QT Interval Dispersion, Non-invasive Marker of Ischemic Injury in Patients with Unstable Angina Pectoris? Jpn Heart J, 2000;41:597-602

7. Cannon, C.P. and Braunwald, E., 2011. Unstable angina and non-ST Elevation Myocardial Infarction. In : R.O.Bonow, D.L. Mann, D.P. Zipes and P. Libby, eds. 2011. Braunwald's Heart Disease: A Text Book of Cardiovascular Medicine. Philadelphia: Elsevier Saunders. Ch. 56.

8. Kramer,B.,Brill,M., Brunhn ,A., and Kubler,W. Relationship between the degree of coronary artery disease and of left ventricular function and the duration of the QT-interval in ECG $^{*}$, Eur Heart $J$ 1986;7(1):14-24.

9. Polychronis, Â. Effects of ischemia on QT dispersion during spontaneous anginal episodes, Journal of electrocardiology, 1999;32(3):199-206.

10. Sharafat N., Khalequzzaman M., Akhtaruzzaman M., Choudhury A., Hasem S., Choudhury T. Prolonged QTc dispersion correlates with coronary artery disease in acute ST elevated myocardial infarction (STEMI) Cardiovasc J. 2013;5(2):173-181.

11. Yunus A., Gillis A.M., Traboulsi M., Duff H.J., Wyse D.G., Knudtson M.L., Mitchell L.B. Effect of coronary angioplasty on precordial QT dispersion , American Journal of Cardiology, 1997;79(10): 1339-1342.

12. Cannon, C.P. and Braunwald, E., 2011. Unstable angina and non-ST Elevation Myocardial Infarction. In : R.O.Bonow,
D.L. Mann, D.P. Zipes and P. Libby, eds. 2011. Braunwald's Heart Disease: A Text Book of Cardiovascular Medicine. Philadelphia: Elsevier Saunders. Ch. 56.

13. KAUTZNER, J. and MALIK, M. QT Interval Dispersion and its Clinical Utility. Pacing and Clinical Electrophysiology, 1997;20: 2625-2640. doi:10.1111/j. 1540-8159. 1997. tb06112.x

14. Savelieva, I., Camm, AJ. And Malik, M., 1993. QT dispersion should be adjusted for age: observations from 1096 normal subjects (abstr), J Am Coll Cardiol, 33, Suppl A:129A.

15. Y. Zhang, W.S. Post, E. Blasco-Colmenares, et al. Electrocardiographic QT interval and mortality: a metaanalysis Epidemiology, 22 (2011), pp. 660-670

16. Stierle U, Giannitsis E, Sheikhjdeh A. Relation between QT dispersion and the extent of myocardial ischemia in patients with three vessel coronary artery disease. Am J Cardiol $1998 ; 81: 564-8$

17. Chugh S N., 2006. Text book of clinical electrocardiography, $2^{\text {nd }}$ edition. New Delhi: Jaypee brothers medical publishers(P) 1td. Cin, VG.,Celik, M., and Ulucan, S.,1997. QT Dispersion Ratio in patients with Unstable Angina Pectoris, Clin. Cardiol. 20:533-535.

18. R. Yilmaz, R. Demirbað, M. Gur., 2006. The association of QT dispersion and QT dispersion ratio with extent and severity of coronary artery disease Ann Noninv Electrocardiol, 11 (2006):43-51.

19. H. Tikiz, T. Terzi, Y. Balbay, A.D. Demir, M. Soylu, T. Keles, et al.QT dispersion in single coronary artery disease: is there a relation between QT dispersion and diseased coronary artery or lesion localization? Angiology, 52 (1) (2001), pp. 43-51

20. Uddin, Moyeen., 2011. Association of central pulse pressure with the extent of angiographically detected coronary artery disease, MD (cardiology), Theses, Dhaka University.

21. Choi,KJ., Lee, CW., Kang,DH.,Song,JK., Kim,JJ.,Park,SW., Park,SJ., Park,CH., Kim,YH. Change of QT Dispersion After PTCA in Angina Patients.Annals of Noninvasive Electrocardiology, 1999;4(2):195-199.

22. Takase,B., Tujimoto,T.,Kitamura, Humbe, A.,Uehata, A.,Kasuseze, I., Satumura, K.,Ohsuzu, F., Kuritam, A. Angioplasty Decreases Prolonged QT Dispersion in Patients with Angina pectoris But Not in Patients with Prior Myocardial Infarction Clin. Cardiol. 2001;24:127-131.

23. Alasti, M., Adel, M.H., Torfi, E., Noorizadeh, M.,Bahadoram, S., Moghaddam, MA., Bahadoram, M., Omidvar, B., Jadbabaei, MH. QT Dispersion: Does It Change after Percutaneous Coronary Intervention? J Teh Univ Heart Ctr ; 2011;6(1):1923.

24. Bruyne,de., Hoes,A. W., Kors,J.A., Hofman,A., Bemmel,J. H and Grobbee,D. E. Prolonged QT interval predicts cardiac and all-cause mortality in the elderly,European Heart Journal, 1999;20:278-284. 